\title{
LA POESÍA VISUAL EN DÍAS DEL CIELO: LA FOTOGRAFÍA DE LA SEGUNDA UNIDAD
}

\author{
Miguel Carrillo Román
}

\section{RESUMEN}

El director de cine Terrence Malick ha desarrollado gradualmente un estilo narrativo de carácter poético, el cual no depende del diálogo sino de el aspecto visual para expresar el relato a través de imágenes. Puesto que la dirección de fotografía cobra una gran relevancia en la obra de Malick, el propósito de este estudio consiste en poner de manifiesto la manera en la que el director de fotografía de la segunda unidad se convierte en un elemento vital dentro del estilo cinematográfico de Malick. Ya que Días del cielo es una pieza clave en la evolución de el trabajo de Malick, este filme será el foco de atención de el siguiente artículo, el cual se basa en información extraída de entrevistas al director de fotografía de la segunda unidad Paul Ryan (entre otros colaboradores) y análisis del montaje y del guion de este filme. PAlabras Clave: Terrence Malick, director de fotografía, segunda unidad, narración visual, cinematografía.

\section{THE VISUAL POETRY IN DAYS OF HEAVEN: SECOND UNIT PHOTOGRAPHY}

\section{Abstract}

Filme director Terrence Malick has gradually developed a poetic narrative style that does not rely on dialogue but on visuals to express the story through images. Since cinematography is of great relevance in Malick's work, the aim of this study is to highlight the way in which the second unit cinematographer becomes a vital element in Malick's filme style. As Days of Heaven is a cornerstone in the evolving style of Malick's work, this filme will be the point of focus for this research, which draws on interview material from second unit cinematographer Paul Ryan (as well as other collaborators), editing analysis, and the script of the filme.

KEYWORDs: Terrence Malick, cinematographer, second unit, visual narrative, cinematography. 
Terrence Malick expresó en una de sus raras entrevistas: «I'm not really interested in just a story, we have to have a feeling; it's not about the words only, it's about the feeling that you have from the imagery»" (Hintermann, Villa, Barcaroli, 2015: 141).

Roger Ebert ${ }^{2}$ hacía referencia a Días del cielo (Days of Heaven, Terrence Malick, 1978) como una de las películas más bellas jamás rodadas (Ebert, 1997). De hecho, en 1977, en la sala de montaje, Terrence Malick y su editor Billy Weber ${ }^{3}$ sintieron una gran inquietud inducida por las imágenes que estaban contemplando; las escenas capturadas en celuloide eran tan cautivadoras que temieron que el filme fuese meramente juzgado por este aspecto (Schneider, Schneider y Malick, 2010).

Días del cielo es un filme bastante peculiar debido a una serie de factores que, combinados entre sí, propiciaron la gestación de la que se convertiría en una de las obras clave de su director: la ausencia de diálogo, el valor pictórico de cada fotograma, el montaje elíptico de sus planos y escenas y el uso mayoritario de luz natural contribuyen a que esta película destaque entre la mayoría de las producciones de su época y haya pasado a ocupar un lugar privilegiado en la historia del cine, habiendo sido seleccionada por el National Filme Registry en 2007 para asegurar su conservación.

La estética de Días del cielo fue diseñada por artistas, en lugar de artesanos. Malick abordó este proyecto con la intención de crear algo que se alejara de lo común, una obra que mantuviese su calidad a través del tiempo y que no se convirtiese en un producto más de la industria cinematográfica. Néstor Almendros (director de fotografía), Jack Fisk (dirección de arte), Patricia Norris (diseño de vestuario) y Billy Weber (montador/editor) lideraron los distintos departamentos encargados de crear la parte visual de el filme, y su colaboración daría como resultado una obra cuya armonía entre los distintos elementos está fundamentada en el campo del arte.

El trabajo que Almendros ${ }^{4}$ realizó en este filme marcaría un antes y un después en su carrera, tanto a nivel profesional como artístico. La gran libertad creativa, el enfoque ampliamente naturalista y la confianza depositada (e infundida) en él por parte de Malick contribuyeron a que este director de fotografía español alcanzase una posición destacada en la industria cinematográfica internacional; no sólo consiguió el óscar a la mejor Cinematografía, sino que, gracias a esta película, Almendros adquirió una exposición artística mucho mayor de la que había conseguido hasta ese momento.

${ }^{1}$ (N. del T.) Realmente no me interesa sólo la historia, debe haber un sentimiento; no se trata sólo de las palabras, se trata de la emoción que te generan las imágenes.

${ }^{2}$ Roger Ebert era un popular crítico norteamericano de cine (1942-2013).

3 Billy Weber ha trabajado junto con Malick en cinco de sus filmes hasta la fecha, generalmente como montador, con la excepción de El nuevo mundo (The New World, Terrence Malick, 2005), donde figura como productor asociado.

${ }^{4}$ Malick se interesó en Almendros especialmente por el trabajo que éste realizó en el filme de François Truffaut El pequeño salvaje (L'Enfant sauvage,1970), una película de época rodada con mínimas fuentes de iluminación artificial (Fox y Riley, 1978). 
Sin embargo, el metraje de Días del cielo fue el resultado de la combinación del trabajo de tres directores de fotografía distintos. Aparte de Almendros, hubo otros dos colaboradores que se encargaron de rodar distintas escenas y planos que acabaron formando gran parte de el montaje final: Haskell Wexler (fotografía adicional) y Paul Ryan ${ }^{5}$ (director de fotografía de la segunda unidad).

No obstante, como el propio Almendros (1990) señala, «los elogios que se han prodigado a mi trabajo desde el Oscar tendrían que ser repartidos entre estos técnicos anónimos» (p. 180). Pese a que en la anterior frase Almendros se refería principalmente a los operadores de cámara que trabajaron directamente con él en este filme, también alude al director de fotografía Paul Ryan por el trabajo que realizó en la segunda unidad. Sobre el metraje rodado por Haskell Wexler, Almendros (1990) comenta: «Dudo que nadie pueda distinguir entre lo rodado por él y lo rodado por mí. En escenas donde hay planos de los dos, hasta a mí me resulta difícil» (p. 181). Con todo, aparte del comentario al inicio de este párrafo no hay apenas referencias al trabajo realizado por Ryan; no ha sido hasta recientemente cuando Ryan ha aparecido en un par de publicaciones ${ }^{6}$ en las que se le entrevista acerca de su trabajo en la obra de Malick. En parte, esto puede ser debido al hecho de que tan sólo Malick, Weber y el productor Harold Schneider sabían que Ryan estaba rodando en Montana mientras el rodaje de la unidad principal tenía lugar en Canadá

Como se expone más adelante, la obra de Malick se expresa considerablemente de un modo visual y mantiene una fuerte relación con la naturaleza y los distintos elementos que forman parte de ella; sirviéndose de esta temática, Malick elabora un tipo de narración que depende de manera sustancial del material obtenido por segundas unidades (empleando incluso, a veces, terceras unidades). Éstas difieren de la unidad principal en el contenido de su metraje; mientras que Malick y el director de fotografía de la unidad principal trabajan con los actores, las segundas unidades se encargan normalmente de conseguir un tipo de material que posteriormente será utilizado en el montaje de forma expansiva y expresiva. Es por ello por lo que este artículo pretende poner de manifiesto la relevancia de la segunda unidad en el trabajo de Malick.

${ }^{5}$ Aunque es bien sabido que Haskell Wexler relevó a Néstor Almendros en el rodaje de Días del cielo, pocos señalan al trabajo que Paul Ryan realizó posteriormente junto con Malick (en la primera unidad), rodando parte de escenas y planos adicionales que eran requeridos para el montaje final de este filme.

${ }^{6}$ Se puede encontrar información sobre el trabajo de Paul Ryan con Malick en Terrence Malick: Rehearsing the Unexpected (2015) y All Things Shining: An Oral History of the Films of Terrence Malick (2017).

${ }^{7}$ El rodaje de la segunda unidad se mantuvo en secreto debido a razones sindicales; Días del cielo era una producción IA (Independent Artist); sin embargo, no está claro que Paul Ryan estuviese registrado en esta categoría (Maher, 2017). 


\section{LA AUSENCIA DEL DIÁLOGO}

El uso de saltos de montaje, cambios de plano o fundidos, entre otros aspectos, converge en Días del cielo dando como resultado una película que recibió bastante críticas por su inusual montaje y la escasez de diálogo. La forma en la que Malick decidió enfocar la narración en su segundo filme resultó un tanto enigmática para el público en general, ya que el diálogo no era el principal motor de la trama, lo cual favoreció que este filme se aproximase más a los términos del cine mudo de principios del siglo xx que al Nuevo Hollywood de los 70 .

Malick pertenece a la categoría de directores que poseen conocimiento sobre fotografía e iluminación y se involucran en el proceso creativo de la estética visual de sus filmes; en Días del cielo este director desarrolló una obra en la cual las imágenes expresan mucho más que las palabras. Esta práctica de narración visual es compartida especialmente por numerosos directores de fotografía, puesto que su labor consiste en gran medida en expresar a través de elementos visuales lo que no es articulado mediante el uso de las palabras; sobre este tema Vilmos Zsigmond ${ }^{8}$ mantiene:

I don't think that movies should be made because of the dialogue. I think it should have a good story; I think the important thing has to be how it is told visually and dialogue should be like music in a film (Glassman, Samuels y McCarthy, 1992, min. 49: 25).

Días del cielo se convirtió en una obra cuya narración está fundada sobre una estructura aún más visual (y por lo tanto más arraigada a los orígenes de el séptimo arte) de lo que inicialmente había sido concebida; la carencia de diálogo resulta en una obra que se ve enriquecida mediante el uso de las imágenes, las cuales son utilizadas como recursos estilísticos comparables a la metáfora o el símil en literatura. Parte de estas imágenes hacen alusión a la naturaleza y el entorno en el que transcurre la historia; pese a que este tipo de material no parece aportar elementos que ayuden al avance de la trama, su presencia contribuye a la creación de una atmósfera de la que Malick se sirve para transmitir distintas sensaciones. Gran cantidad de estas imágenes fue rodada por Ryan, junto con Jacob Brackman (director de la segunda unidad).

Sobre el papel, Malick es capaz de crear un tipo de narrativa que es definida a menudo como poética; esto se debe en parte al uso de distintas formas retóricas que enriquecen la narración, al mismo tiempo que sugieren la existencia de un universo mucho más amplio y complejo de lo que muestran las acciones de los

${ }^{8}$ Vilmos Zsigmond (1930-2016) fue uno de los directores de fotografía más influyentes en Hollywood, habiendo colaborado con directores como Robert Altman, Steven Spielberg o Michael Cimino.

9 (N. del T.) No creo que las películas deban hacerse por el diálogo. Pienso que debe haber una buena historia; creo que lo importante es como ésta se narra visualmente y el diálogo debería ser como música en un filme. 
personajes. El guion de Días del cielo, escrito por Malick, contiene una cantidad de líneas de diálogo mayor que el filme. En la etapa de rodaje, sin embargo, Malick se percató de que parte de ese diálogo tendría que ser cortado o de lo contrario el resultado final sería demasiado extenso (Mediafunhouse, 2007). No obstante, fue la etapa de montaje la que definiría la evolución de este filme; la experimentación llevada a cabo por Weber y Malick con el enlace de distintos planos, a veces extraídos de escenas fuera de contexto (Beyda, 2013), favoreció el desarrollo de una narración ampliamente dependiente de las imágenes, resultando en la exclusión de gran parte del diálogo que figuraba inicialmente en el guion. Cabe mencionar que durante este proceso también fue incluida la voz en off de Linda Manz ${ }^{10}$. De esta forma, la obra final difiere en cierta medida del concepto inicial.

La popular crítica de cine Pauline Kael (2013) describió Días del cielo como un árbol de navidad vacío, haciendo hincapié en la ausencia de diálogo y lo mucho que el espectador echa en falta este factor. Sin embargo, las imágenes hablan por sí mismas y quizá de una manera más delicada que el diálogo. Sin ir más lejos, en la escena en que los cuatro protagonistas se acercan a las vías del ferrocarril para ver pasar al presidente en tren, las imágenes no necesitan ningún tipo de exposición verbal para que podamos comprender lo que Bill (Richard Gere) siente en esa escena. Después de que el tren haya pasado, el granjero (Sam Shepard) ayuda a Abby (Brooke Adams) a subir a la carroza; esta imagen se muestra en un plano entero y está rodada con un teleobjetivo, desde el punto de vista de Bill, y revela la delicadeza con la que el granjero toca a Abby, el amor con el que la mira y la felicidad que la compañía de esta persona le produce. Como contraposición, tras esta imagen vemos el rostro de Bill en un primer plano (figura 1), quien observa la escena en la distancia; la expresión en su mirada pone de manifiesto el dolor que los celos le producen, el miedo de perder a Abby y la aflicción de haberle pedido que tomase parte en su plan para heredar el dinero del granjero. Pero los labios de Bill no dejan escapar ni una sola palabra. Su expresión transmite más que cualquier línea de diálogo. Existen numerosas escenas como ésta en el filme, y son la composición, la luz y el movimiento de cámara los que hablan por sí solos. También cabe destacar que Malick y Almendros se inspiraron (entre otros) en el trabajo de pioneros del cine mudo como Griffith o Chaplin. Sobre estas influencias, Charles Silver comenta lo siguiente:

Days of Heaven challenges the viewer to work a bit harder than «traditional» movies, but it is in some ways a throwback to the glory days a half-century earlier when silent films had attained a level of visual elegance (much of it due to the use of natural lighting) that was lost or understated in much of the sound era ${ }^{11}$ (Silver, 2014: párr. 2).

Gere).

${ }^{10}$ La actriz Linda Manz interpreta el papel de Linda, la joven hermana de Bill (Richard

${ }^{11}$ (N. del T.) Days of Heaven desafía al espectador a trabajar un poco más duro que las películas «tradicionales», pero es en cierta forma una vuelta a los días de gloria de hace medio siglo 


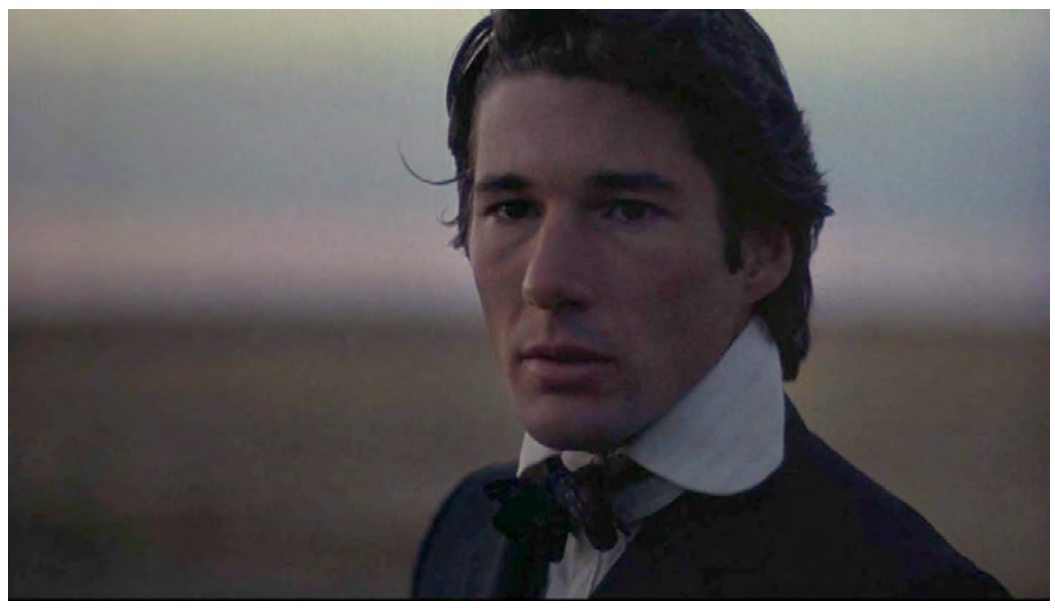

Figura 1. Días del cielo, 1978.

Cabe añadir que, junto a la escasez de diálogo, la luz cobra un significado bastante especial en este filme, ya que en lugar de intentar recrear la iluminación de la época (la trama transcurre en 1916) con fuentes de luz artificiales y dentro de un estudio, Malick y Almendros recurrieron a la simplicidad y al naturalismo, capturando una realidad cuya principal aspiración parecía ser la de abrir una ventana al pasado.

\section{EN BUSCA DE IDEAS, MEMORIAS Y SUEÑOS}

La brisa acariciando una pradera, el grácil vuelo de una garza o la cálida luz del sol entrando por una ventana; estas imágenes, las cuales comparten un mismo origen, poseen un carácter etéreo y contienen un significado ambiguo. A través de la obra de Malick este tipo de planos es empleado con una intención claramente alegórica, lo cual representa una de las características principales que definen su estilo y le separan de el resto, debido a que este tipo de planos no suelen ser utilizados de esta forma en el cine mainstream. Como Jacob Brackman expresa:

The ability to see things is, in a way, Terry's signature. He kind of invented that way of putting a movie together and relying on this unusual dimension of nature, animals, sky, birds, and trees -basically, second unit kind of stuff that most

cuando el cine mudo había adquirido un nivel de elegancia visual (en gran parte debido al uso de iluminación natural) que se perdió o fue subestimado en gran parte de la era del cine sonoro. 
filmmakers don't have in their arsenal because they haven't spent the time shooting that kind of material. From this way of shooting his marvellous, distinctive style was born ${ }^{12}$ (Hintermann, et al., 2015: 134).

Esta clase de material es (en su mayoría) capturado por la segunda unidad y suele ser empleado como planos de establecimiento, planos recurso, planos subjetivos, y atmospheric insert shots ${ }^{13}$. Suelen ser planos de corta duración (con una media de cinco segundos en este filme) aunque algunos alcanzan una excepcional duración (como el plano que aparece en el minuto 1:02:46, con una extensión de 13 segundos) para un plano de este tipo. Aparecen entre diferentes escenas o en mitad de éstas, y en general muestran elementos de la geografía, flora y fauna, así como distintos fenómenos climatológicos. Así pues, la mayor parte de esta clase de metraje está compuesta por planos de la naturaleza, la cual está presente en todo momento durante el filme y comparte protagonismo con el resto de los personajes; obviamente, es el montaje de este material el que favorece la creación de una estructura narrativa que, en el caso de Días del cielo, se sustenta de este tipo de imágenes, las cuales adquieren aquí una nueva entidad representativa. Sobre el carácter de este tipo de planos en el cine de Malick, Dave Kher opina lo siguiente:

Malick frequently inserts shots of animals - horses, dogs, particularly birds- that comment on the action in a direct evocation of Eisenstein's associative montage style. [...] But beyond that, the animal imagery links the human drama to a bigger story-a play of elemental emotions and instincts, the cycles of nature ${ }^{14}$ (Kher, 2011: 25).

En cuanto al empleo de metraje con un amplio contenido de elementos naturales por parte de Malick, Ben McCann comenta: «A clearly recognisable visual atmosphere is constructed and the narrative is driven as much by setting as character, so that nature, or more abstractly, the construction and use of natural space,

12 (N. del T.) La habilidad para ver cosas es, en cierto sentido, la marca de Terry. En cierto modo él inventó esta forma de montar una película y depender de esa inusual dimensión de la naturaleza, animales, cielo, pájaros y árboles; básicamente, metraje de la segunda unidad que la mayoría de directores no posee en su arsenal porque no han dedicado tiempo a rodar este tipo de material. De esta forma de rodar nació su maravilloso y distintivo estilo.

${ }^{13}$ Un plano atmospheric insert es aquél reconocible porque no tiene una función específica en el avance de la trama y tampoco es un plano desde el punto de vista de los personajes; por lo tanto, su misión es aportar una cierta atmósfera o emoción a la narración en el momento apropiado (Barry Salt, 2009).

${ }^{14}$ (N. del T.) Con frecuencia Malick inserta planos de animales - caballos, perros, especialmente pájaros- que comentan sobre la acción en una evocación directa al estilo de montaje asociativo de Eisenstein. [...] Pero más allá de esto, las imágenes de animales conectan el drama humano a una historia mayor, un juego de emociones e instintos elementales, los ciclos de la naturaleza. 
assumes a vital aesthetic and narratological function $»^{15}$ (Patterson, 2003: 76). Por lo tanto, obtener este tipo de imágenes se convierte en un factor fundamental para Malick, y aunque a veces él mismo se encarga de capturar alguno de estos planos mientras trabaja con la unidad principal, esta tarea requiere la dedicación completa de la segunda unidad.

Generalmente, en la mayoría de las producciones la segunda unidad se encarga de rodar planos que funcionan a modo de piezas conectoras entre escenas o planos que requieren de algún tipo de información visual adicional para ilustrar la narración y guiar al espectador; en el caso de Malick, estas reglas no se aplican y la segunda unidad se caracteriza por la búsqueda de material que pueda ser utilizado para canalizar, expresar y representar contenido por sí mismo. De esta forma, en el cine de Malick, estas imágenes no son meros nexos de unión, como Ryan mantiene:

I met with Terry and together we grease-penciled the script, outlining specific moments, epiphanic moments where the second unit footage wasn't used to connect scenes, but were meant to coexist with the scenes with actors. It was just as important ${ }^{16}$ (Maher, 2017: 94).

Aunque si bien es cierto que es uno de los tópicos primordiales, no es solamente la naturaleza el foco de atención de la segunda unidad. En otras ocasiones, son los objetos cotidianos los que reciben la atención de la cámara. Malick confiere una especial importancia a diversos elementos que, debido a su naturaleza ordinaria, pasan desapercibidos para la mayoría. Estos objetos aparecen a veces (como se demuestra más adelante) en mitad de escenas con gran peso en la trama, y por lo tanto parecen albergar un significado especial, puesto que no son un plano subjetivo de ninguno de los personajes ni tampoco éstos hacen alusión a dicho objeto mientras conversan. Como Hwanhee Lee reflexiona al respecto, «Malick makes the objects emerge as things tend to hide in the background of human lives and conflicts, just as nature loves to 'hide' in the background of human affairs, particularly in the forms of life that we inhabit ${ }^{17}$ (Lee, 2007: 19). Esta manera de abordar el proceso narrativo fomenta que el aspecto cinematográfico cobre una mayor importancia en el cine de Malick, ya que los directores de fotografía no se limitan a rodar planos de acuerdo a lo que dicta el guion; el director de fotografía debe sincronizar su forma de ver y pensar con la de Malick, quien en todo momento persigue las imágenes que puedan representar el sentimiento que la historia intenta transmitir.

15 (N. del T.) Se construye una atmósfera visual claramente reconocible y la narración es conducida tanto por el marco como por los personajes, por lo que esta naturaleza, o de manera más abstracta, la construcción y el uso de el espacio natural, asume una función estética y narrativa vital.

${ }^{16}$ (N. del T.) Me reuní con Malick y juntos subrayamos el guion, destacando momentos específicos, momentos epifánicos donde el metraje de la segunda unidad no se usaría para conectar escenas, sino que estaba destinado a coexistir con las escenas de los actores. Era igual de importante.

${ }_{17}$ (N. del T.) Malick hace que los objetos emerjan, así como las cosas tienden a esconderse en el fondo de las vidas y conflictos humanos, de la misma forma que a la naturaleza le encanta esconderse en el segundo plano de los asuntos humanos, particularmente en las formas de vida que habitamos. 
En la producción de El árbol de la vida (The Tree of Life, Terrence Malick, 2011) la segunda unidad trabajó durante la misma cantidad de tiempo que la unidad principal, incluyendo la colaboración con actores, y su tarea no se limitaba sencillamente a capturar imágenes bellas, sino que más bien se podría definir como "gathering thoughts, memories, and dreams $»^{18}$ (Edwards, 2014: párr. 6).

La narración en el guion de Días del cielo, escrito por Malick, está redactada de una forma similar a la estructura visual del filme. Aun cuando una acción o un plano (que en términos narrativos podrían parecer aparentemente triviales) son descritos sobre el papel, Malick utiliza una retórica enfocada a la evocación de un concepto onírico, el cual no aporta ninguna información trascendente para el argumento pero crea sin embargo una imagen de tipo impresionista que ańade a la escritura un tono lírico. A menudo, en el guion, Malick hace uso de el símil para incitar la gestación de una emoción, como demuestra la frase «Independent of his will, the truth is forcing its way up, like a great blind fish from the bottom of the sea ${ }^{19}$ (Malick, 1976: 105). Quizá sea éste el elemento más característico de el estilo cinematográfico de este director: la forma en la que recurre a la yuxtaposición visual de la naturaleza y las emociones de los personajes para crear un sentimiento inefable. De esta forma, el diálogo asume un papel secundario en la narración del relato, debido a que el uso de la fotografía está dirigido hacia la representación no verbal de la trama. Cabe resaltar que, en alguna de las escenas escritas en el guion, la descripción de la acción va acompañada a veces de información extra que visualmente no será expuesta en el filme, pero que detalla de una forma ilustrativa una emoción o una sensación, la cual probablemente está enfocada a una mayor comprensión de los personajes por parte de los actores, como se puede apreciar en las líneas "Chuck ${ }^{20}$ holds a handful of seed under his nose. His heart stirs at the dark, mellow smell $\aleph^{21}$ (Malick, 1976: 89).

El símil y la metáfora encuentran su camino a través de diversos aspectos en el trabajo de Malick. Estas figuras retóricas parecen formar parte de el modo en que este director interpreta y expresa sus pensamientos; no sólo las utiliza Malick en la redacción de sus guiones, sino que también las emplea cuando trabaja con actores. A veces, para inducir un estado de ánimo o una emoción en el actor, Malick plantea sus direcciones de una manera romantizada, como el actor Kirk Acevedo ${ }^{22}$ recuerda: «One of Terry's notes for me was 'Now, Kirk, you are on a ship and the

${ }^{18}$ (N. del T.) Recolectar ideas, memorias y sueños.

19 (N. del T.) Independientemente de su voluntad, la verdad asciende abriéndose paso a la fuerza, como un enorme pez ciego desde el fondo del mar.

${ }^{20}$ Chuck es el nombre que Malick utilizó en el guion para el personaje de el granjero (interpretado por Sam Shepard), pese a que en el filme nunca se nombra e incluso en los títulos de crédito aparece como The Farmer.

${ }^{21}$ (N. del T.) Chuck sostiene un puñado de semillas bajo su nariz. Su corazón se estremece ante el oscuro aroma apacible.

${ }^{22}$ Kirk Acevedo es el actor que interpreta a Pvt. Tella en La delgada linea roja (The Thin Red Line, Terrence Malick, 1998). 
beach is right there; and you are calling out into the abyss... and that's where your motivation is' ${ }^{\prime 23}$ (Geisler, Roberdeau, Hill y Malick, 2010: min. 24:12). De cualquier forma, la retórica de la que Malick se sirve parece estar siempre enfocada al elemento visual, ya que en general, ya sea a través del papel, el celuloide o la conversación, Malick se vale de la imagen para manifestar la idea que quiere transmitir. Naturalmente, ésta es una cualidad que debe ser compartida y entendida por sus colaboradores, en concreto aquéllos que se encargan de diseñar la estética visual del filme; Haskell Wexler comenta sobre este aspecto: «Terrence Malick is a very intense, dedicated, visually concerned person who communicates in less traditional ways. It doesn't mean he doesn't communicate, but it requires a sensitive director of photography $»^{24}$ (Hintermann et al., 2015: 97).

Así pues, se podría afirmar que el estilo narrativo de Días del cielo se basa en gran parte en el uso de matices visuales efímeros, los cuales son representados por planos que hacen alusión al carácter poético del guion. Estos planos son utilizados en el filme de una forma un tanto pictórica, pues se transforman en pequeńas pinceladas que van creando formas y colores sobre la pantalla e indudablemente contribuyen a la creación de la imagen final; en este caso, esa imagen está compuesta a su vez por miles de otras imágenes en movimiento. De este modo, el resultado final es el filme en su totalidad, lo que Tarkovsky definiría como un mosaico hecho de tiempo (Tarkovskiǐ y Gianvito, 2006).

Son por lo tanto estas imágenes las que ilustran las distintas sensaciones que constituyen parte de la narración y, a su vez, acabaron sustituyendo gran parte del diálogo en Días del cielo. Como el guion de este filme muestra, este tipo de planos independientes fueron concebidos por Malick desde el inicio; se encuentran diseminados a lo largo de el relato y poseen a veces un tono melancólico, como cuando Malick (1976) escribe: «Nightingales call out like mermaids from the sea» (p. 53) o «Some buffalo appear on the crest of the next hill. [...] They do not seem quite part of this world but mythical, like minotaurs $»^{25}$ (p. 73). Esta última frase contiene un carácter elegíaco y épico al mismo tiempo, el cual reitera un sentimiento ligado a la nostalgia que es patente (al menos) en las cinco primeras películas de Malick, las cuales contienen una trama (principal) que transcurre en un tiempo pasado.

Uno de los elementos a resaltar en la narración utilizada por Malick es que podría considerarse un tanto ambiciosa; parece querer abarcar al mismo tiempo la inmensidad y la minucia contenidas en su relato (y en la vida misma). Por otro lado, este aspecto es propio del lenguaje del cine, es decir, este medio ofrece la oportunidad de combinar instantáneamente escalas totalmente dispares. Durante Días del

${ }^{23}$ (N. del T.) Uno de los apuntes de Terry para mí era «Kirk, tú estás en un barco y la playa está justo ahí; y tú estás gritando en el abismo... y ahí es donde se encuentra tu motivación».

${ }^{24}$ (N. del T.) Terrence Malick es una persona muy intensa, dedicada y con gran interés en las imágenes que no se comunica en la forma habitual. Eso no significa que no se comunique, pero requiere un director de fotografía sensible.

25 (N. del T.) Ruiseñores cantan como sirenas desde el mar. Algunos búfalos aparecen en la cima de la colina más próxima. [...] No parecen de este mundo sino míticos, como minotauros. 
cielo, podemos ver planos de inmensos campos de trigo (a menudo en un gran plano general); en estos planos podemos observar el mundo que habitan los personajes, el cual está siempre envuelto por una estética que persigue la belleza visual. En otros momentos, Malick enfoca su interés en el detalle, en la fragilidad de los elementos pequeños y efímeros. En una de las escenas, la atención del director se centra en la germinación de una semilla ${ }^{26}$ bajo tierra, mostrándonos de este modo la naturaleza reducida y misteriosa que escapa a la mayoría de las personas, pero que al margen de su atención sigue su curso.

El tipo de imágenes mencionadas en el párrafo anterior, las cuales provienen del metraje rodado por la segunda unidad, encuentran un lugar privilegiado en el trabajo de Malick, conviviendo con las imágenes creadas por la primera unidad y enriqueciendo el mundo diegético de Días del cielo. El interés de Malick parece no conocer fin, y es por ello por lo que la cámara presta la misma atención a acontecimientos de diversa índole. Por lo tanto, la narración se ve nutrida por el uso de estos atmospheric inserts shots, los cuales, a pesar de estar diseminados a través del filme, van creando una cierta sensación que desemboca en la impresión final que el filme genera en el espectador. Richard Combs comenta al respecto:

Malick's narrative method, in fact, has more to do with this selective accretion of detail than with telling a story or developing a set of characters. It is a method which has a peculiarly literary flavour, not surprising perhaps given his invocation of What Maisie Knew as a model for Linda's commentary, but certainly a unique way of containing the visual superabundance of the film ${ }^{27}$ (Combs, 1979: 111).

Como señala Combs, es esta acumulación de detalles la que resulta fundamental para comprender el estilo narrativo de Malick, ya que la esporádica aparición de este tipo de metraje, junto con la cinematografía, montaje y sonido, va consolidando poco a poco un lenguaje visual propio a través de la película.

Debido a este lenguaje narrativo-visual, las obras de Malick suelen dividir a la crítica (y audiencia); gran parte de las reseńas acostumbran a hacer referencia a la hegemonía de las imágenes sobre el diálogo y el relato, como dice Roy Anker (2010), «because Malick's remarkable visual storytelling seems at times to overwhelm narrative focus $»^{28}$ (párr. 11). Lo cierto es que con frecuencia, Malick parece más interesado en la exploración de momentos emancipados que orbitan en torno a una idea

${ }^{26}$ Esta escena es utilizada en este caso a modo de elipsis temporal. El material fue rodado por Ken Middleham mediante la técnica de time-lapse. Dicha escena figura en el guion: «The seeds germinate in the darkness of the soil» (Malick, 1976: 90). Incluso se especifica el uso de time-lapse.

27 (N. del T.) El método narrativo de Malick, de hecho, tiene más que ver con la adición selectiva del detalle que con la narración de una historia o el desarrollo de unos personajes. Es un método que tiene un peculiar sabor literario, no especialmente sorprendente quizá debido a su invocación a What Maisie Knew como modelo para el comentario de Linda, pero sí ciertamente único en su manera de contener la superabundancia visual de el filme.

${ }^{28}$ (N. del T.) Porque la excepcional narración visual de Malick parece abrumar a veces el punto de atención del relato. 
principal que en la propia narración de una historia. Janine Utell reflexiona sobre este aspecto basándose en el filme El árbol de la vida:

... the filme doesn't really «tell a story.» It presents certain recognizably narrative elements that a viewer can piece together into a story, and part of the filme is dominated by the narrative mode, with a discernible arc, events, and characters. But it depends just as heavily on purely visual components whose purpose is not immediately clear ${ }^{29}$ (Utell, 2015: 92).

El paisaje es, en su conjunto, otro de los aspectos esenciales en el cine de Malick. En Días del cielo, el entorno que rodea a los personajes resulta fundamental a la hora de reflejar el carácter de éstos y su adaptabilidad a distintos lugares; se puede observar un gran contraste (especialmente en términos de color) entre la urbe de la que los protagonistas escapan al principio del filme, los inmensos campos de trigo de Texas ${ }^{30}$ y la vuelta a la civilización (por un breve período de tiempo) por parte de Abby y Linda hacia el final del filme. Paul Ryan se encargaría de filmar parte de este paisaje ${ }^{31}$, y tal y como él explica "[Malick] said a lot of the filme: would be images of the world surrounding the characters» ${ }^{32}$ (Ryan, 2009: párr. 7).

Además de establecer un cierto tono en las distintas escenas, el paisaje es utilizado en este filme de forma similar a los distintos elementos naturales que hacen su aparición ocasionalmente en los cambios de plano y atmospheric inserts, ya que la forma en la que dicho paisaje fue rodado y, posteriormente, montado cumple una doble función estética-atmosférica con carácter expositivo.

Una de las impresiones que las imágenes de este filme transmiten es la fragilidad del momento y su irremediable fugacidad. La duración de los planos es corta y, por ello, la cautivadora fotografía deja al espectador con la sensación de querer ver más. También, la breve hora mágica, en la que se rodaron numerosas escenas, actúa como metáfora del implacable paso del tiempo y de su preciado valor. Incluso Almendros recuerda tener la sensación de que, en cierta forma, Malick los culpaba a

29 (N. del T.) ... el filme realmente no "cuenta una historia.» Expone ciertos elementos narrativos reconocibles que un espectador puede ensamblar dentro de una historia, y parte del filme está dominada por el modo narrativo, con un arco identificable, acontecimientos y personajes. Pero depende de la misma manera de componentes visuales cuyo propósito no resulta claro de inmediato.

${ }^{30}$ A pesar de que la historia de Días del cielo tiene lugar en Texas, el filme fue rodado en su mayoría en Alberta, Canadá. A causa de continuos retrasos en la producción y a que Néstor Almendros no podía trabajar en Estados Unidos debido a normas del sindicato, el rodaje tuvo que ser trasladado a Canadá (Gandert, 2011).

31 Paul Ryan y Jacob Brackman (director de la segunda unidad y productor ejecutivo) se encargaron de encontrar por su cuenta las localizaciones que consideraron apropiadas; Ryan utilizó un "pequeño avión» desde el cual observaba posibles lugares donde rodar, siempre teniendo en cuenta que no hubiese cables de la línea telefónica o edificios modernos en los alrededores (Hintermann et al., 2015).

32 (N. del T.) [Malick] dijo que gran parte del filme consistiría en imágenes del mundo que rodea a los personajes. 
él y al equipo por no ser capaces de detener el sol mientras rodaban durante la hora mágica (Fox y Riley, 1978).

Por consiguiente, resulta obvio que el aspecto visual posee una enorme relevancia en el trabajo de Malick, y es por ello por lo que las imágenes reciben un cuidado y una atención especiales. Almendros, junto con Wexler y Ryan, consiguió modelar la luz de acuerdo a la visión de Malick; la dirección de fotografía en Días del cielo ocupa un lugar central en la concepción y recepción de esta obra, dado que (junto con el montaje) es el aspecto que la separa del resto y por el cual es mayoritariamente recordada. Cabe resaltar que, desde una etapa bastante temprana de esta producción, Malick mostró gran interés por el uso de la cinematografía como herramienta comunicativa y expresiva; así, se pueden encontrar ciertas líneas en el guion (Malick, 1976) que hacen énfasis específicamente sobre el aspecto visual de la escena, como "A shy, virginal light has descended over the world» (p. 26) o «The moon makes Abby's nightgown a ghostly white» (p. 69) y más concretamente sobre la iluminación en frases como "Chuck lies asleep in a shaft of moonlight next to Abby» (p. 68) y «The locusts mill around crazily on the wheat stalks, backlit against the flame» ${ }^{33}$ (p. 108).

\section{ATMOSPHERIC INSERT (EL CORTE 'MALICK')}

En la escena del regreso de Bill ${ }^{34}$ hay un plano que, en cierta forma, recoge la esencia de la película en su enteridad; además, la forma en la que aparece revela un rasgo significativo de la narración de Malick. El plano consiste en un atmospheric insert de una planta en el interior de la casa del granjero. Esta imagen ilustra en gran medida el lenguaje narrativo de Días del cielo y a su vez representa la película y la temática contenida en ella.

En la escena en cuestión, Bill regresa tras un período de ausencia durante el cual la relación amorosa entre Abby y el granjero se ha consolidado. Bill aparca su motocicleta y no tarda en encontrar a Abby, a quien divisa a través de una ventana, la cual es empleada aquí como un recurso cinematográfico que hace alusión al estado de la relación entre estos dos personajes: Bill ve claramente a Abby a través de la ventana, mientras ella, ajena a su presencia, practica unos pasos de baile; él, sin embargo, aparece en el mismo plano, junto a Abby, pero su figura es tan sólo un reflejo en el cristal (figura 2). Bill queda reducido a una imagen transparente y casi fantasmagórica de su persona, parece desvanecerse del mundo de Abby.

Cuando Abby finalmente ve a Bill, los dos se acercan, se miran; ni una sola línea de diálogo es hablada, y es entonces cuando Malick decide cortar a la imagen

${ }^{3}$ (N. del T.) Una tímida luz virginal ha descendido sobre el mundo. / La luna torna el camisón de Abby en un blanco fantasmal. / Chuck yace dormido en un haz de luz de luna junto a Abby. / Las langostas se pasean alocadamente sobre los tallos de trigo, iluminadas desde atrás por la llama.

${ }_{34}$ Dicha escena comienza en el minuto 1:02:59 de Días del cielo. 


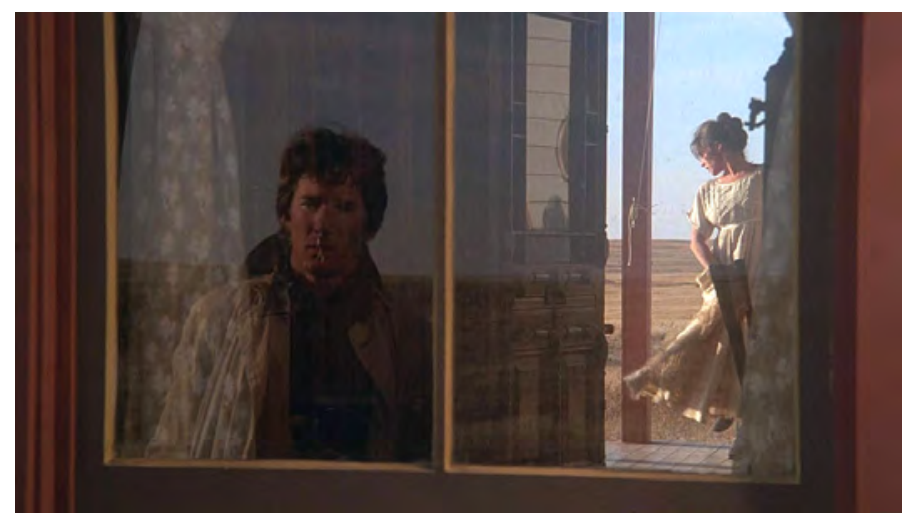

Figura 2. Días del cielo, 1978.

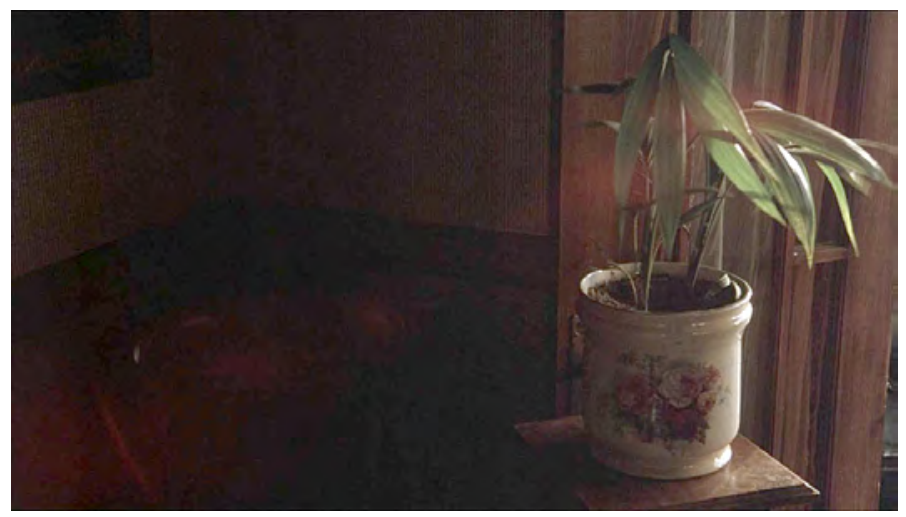

Figura 3. Días del cielo, 1978.

de la planta (figura 3). En un plano diseñado para cargar todo el peso de la imagen a la derecha (dejando el resto del encuadre prácticamente vacío), la imagen (que ya de por sí parece estar fuera de contexto) transmite una sensación extraña, como si algo estuviese fuera de lugar. Vemos la planta en su macetero, con las hojas mecidas apaciblemente por la brisa. Esta planta es un objeto que ya ha aparecido anteriormente en otros planos pero nunca como protagonista absoluto del plano. La importancia que este elemento recibe por parte de Malick resulta un tanto enigmática, pues esta planta no volverá a aparecer en el filme (como centro de atención); aun así, realiza su intrusión en mitad de un momento bastante delicado entre dos personajes principales.

En cierta forma, este plano introduce la planta como testigo de este momento especial, al igual que probablemente lo haya sido de tantos otros, no importa cómo 
de íntimos o triviales fuesen. La planta, como el ser inerte que es, no juzga, tan sólo está presente. En contraposición, las personas sí lo hacen; previamente en la escena, Malick ha mostrado el primer plano del granjero, quien, mirando a través de otra de las ventanas de la casa, presencia el reencuentro entre Bill y Abby. De esta manera, este tipo de planos parece crear la sensación de que la planta «is aware of the subject who is unaware of its presence ${ }^{35}$ (Lee, 2007: párr. 8).

Los objetos, plantas y animales presentes en Días del cielo son ajenos a las circunstancias de los personajes de la historia, pese a que comparten el mismo espacio y forman parte del mismo universo en este filme; a través de ellos Malick expresa la conexión entre las personas y dicho universo. Michel Ciment comenta:

... sin duda, Malick es el más intelectual de los realizadores norteamericanos de su generación, siendo también el más sensual y el más sensible al cosmos, como lo prueba la atención que le presta a la fauna y la flora, al agua y al fuego, tan ampliamente evocados en su cine (Ciment, 2007: 371).

De este modo, la narración de esta película está constituida por abundantes elementos visuales que conviven con la trama, ya que poseen un significado propio y sugieren diversas ideas o emociones. Mientras que parte de estos planos aparecían desde un principio en el guion, otros fueron seleccionados entre el material rodado y añadidos a la historia debido a su valor expresivo. A menudo este tipo de material aparece en el filme a través de secuencias de montaje y es aquí cuando la yuxtaposición de distintos elementos visuales fomenta más claramente la presencia de un carácter poético en el relato. Este carácter hace alusión a una dimensión no tangible, pero que no obstante puede ser percibida, en cierto modo, de una forma similar a la música. Ésta, gracias a su capacidad para provocar una emoción en el oyente, puede ser apreciada incluso por aquéllos que no han estudiado su lenguaje ni conocen la estructura de su composición. Ésta era una de las ideas que rondaba en la mente de Malick durante la preproducción de Días del cielo, como Ryan expone:

He wanted to create something that would give you the same sort of feeling that you would have when you listened to a Beethoven symphony; you don't see exactly what is going on, but you have a very powerful feeling from that about life... I think that was a big part of his filmmaking and I think it is a great thing for a cinematographer to work with that sort of freedom ${ }^{36}$ (Hintermann et al., 2015: 141).

De acuerdo con Almendros, Malick le dijo que «[Días del cielo] would be a very visual movie; he said 'the filme will be a visual filme and the story will be told

35 (N. del T.) Se percata de la presencia de las personas, quienes no se percatan de la suya.

36 (N. del T.) El quería crear algo que produjese el mismo tipo de sensación que sientes al escuchar una sinfonía de Beethoven; no ves exactamente lo que ocurre, pero te aporta una poderosa sensación sobre la vida... Creo que aquello formaba gran parte de su cine y pienso que para un director de fotografía es magnífico trabajar con ese tipo de libertad. 
through visuals' ${ }^{37}$ (Glassman et al, 1992: min. 01:08:59). La decisión de filmar con luz natural (y en color) fue el factor clave que sirvió para definir la estética de esta película. La elección de rodar mayoritariamente durante la hora mágica sin duda elevó la belleza de las imágenes filmadas, así como el uso del sistema Panaglide ${ }^{38}$ añadió dinamismo y fluidez a las escenas, las cuales fueron esculpidas y modeladas gracias al montaje, articulando de esta manera la expresión visual de el filme. Fascinado por una época que ya pasó, e inspirado por la naturaleza, Malick comenta en una de sus escasas entrevistas sobre la cinematografía de este filme:

... I was able to capture absolute reality. That was my wish: to prevent the appearance of any technique, and that the photography was to be processed to be visually beautiful and to ensure this beauty existed within the world I was trying to show, suggesting that which was lost, or what we were now losing ${ }^{39}$ (Maher, 2017: 95).

\section{EL ROL DE LA SEGUNDA UNIDAD}

El modo en que los miembros de la segunda unidad desarrollan su labor en distintas producciones como Dias del cielo, La delgada linea roja (The Thin Red Line, Terrence Malick, 1998) o El árbol de la vida revela la considerable repercusión que su trabajo ejerce en la obra final, así como la responsabilidad que recae sobre este equipo. A su vez, el enfoque adoptado por la segunda unidad a la hora de abordar estos proyectos es distinto al que generalmente se sigue en la industria de Hollywood, y, como se expone a continuación, pone de manifiesto la disposición de carácter colaborativo adoptada por el director en el proceso cinematográfico.

En las producciones de Malick, la segunda unidad trabaja a menudo de forma independiente; el equipo que compone este departamento realiza su labor después de que la primera unidad haya terminado de rodar en un set o localización, aunque con bastante frecuencia se encarga de filmar material en otros lugares, a veces en puntos geográficos bastante alejados de donde se encuentra el director, como ocurrió en la producción de Días del cielo. Esto contribuye a que la segunda unidad disponga de una gran autonomía, la cual se traduce en una relativa libertad en cuanto a la toma de decisiones (siempre dentro de ciertos límites). Ryan explica:

37 (N. del T.) [Días del cielo] sería una película muy visual; él dijo «el filme será un filme visual y la historia será contada a través de imágenes».

${ }^{38}$ El sistema Panaglide era la versión de Panavisión del sistema Steadicam. Días del cielo fue uno de los primeros largometrajes en utilizar este novedoso mecanismo, el cual contribuyó en gran medida a la estética del filme, debido a la fluidez y libertad de movimiento que ofrecía al operador. A causa del peso del sistema Panaglide, éste debía ser utilizado por un operador especializado, en este caso Eric Van Haren Noman, quien trabajaba bajo la supervisión de Almendros (1990).

39 (N. del T.) ... fui capaz de capturar realidad absoluta. Ése era mi deseo: evitar el rastro de cualquier técnica, y que la fotografía fuese realizada para ser visualmente bella y para asegurar que esta belleza existió en el mundo que estaba intentando mostrar, sugiriendo lo que se perdió, o lo que estamos perdiendo. 
I did choose all the locations that I shot for the second unit in Montana, which was mostly the river, the wheat fields and some things in little towns, because Terry and I were never there together; we would talk by phone and he would describe what he wanted and I would shoot it ${ }^{40}$ (Hintermann et al., 2015: 117).

Así pues, parece justo decir que Malick deposita gran confianza en sus colaboradores, a diferencia de otros directores como David Lean, quien de acuerdo con Gene Phillips (2006) «delegated scenes to second unit directors very grudgingly, he wanted to shoot everything himself, suspecting that a second unit director really wanted to make his own film»"${ }^{41}$ (p. 299).

El hecho de que Malick delegue responsabilidad en distintas unidades muestra una faceta relevante de su estilo directivo: su comodidad en el rol de colaborador en lugar de autor absoluto de la obra. Por supuesto, se debe mencionar que su estilo narrativo ha ido evolucionando hacia un enfoque mucho más amplio y disperso que el de la mayoría de directores hollywoodenses. Después de El árbol de la vida, Malick realizó una trilogía ${ }^{42}$ en la que dejó de utilizar el guion y, en su lugar, se centró en la búsqueda de momentos espontáneos, estimulados por un impulso ampliamente improvisador. Este aspecto fomentó el rodaje de gran cantidad de material editorial, puesto que, como consecuencia de seguir este modo de trabajo, la historia que compone sus últimos filmes sería encontrada y cobraría forma mayormente durante el proceso de montaje. Obviamente, una única unidad no sería suficiente para rodar la extensa cantidad de metraje con la que Malick acostumbra a trabajar. En algunas ocasiones, al concluir el rodaje la abundancia de material era tal que algunos personajes fueron totalmente descartados o reducidos a tan sólo unos minutos en pantalla; de hecho, parte del material rodado por una de las segundas unidades en el filme To the Wonder (Terrence Malick, 2013) vio la luz como spin off ${ }^{43}$ en 2018, con uno de los personajes secundarios del filme de Malick ahora como protagonista. El hecho de filmar bastante metraje no es solamente un factor típico de los últimos proyectos, ya que en anteriores ocasiones la cantidad de material que la segunda unidad generó y que acabó siendo utilizado en el filme fue bastante considerable; como Gary Capo, el director de fotografía de la segunda unidad en La del-

40 (N. del T.) Yo elegí todas las localizaciones que rodé para la segunda unidad en Montana, que eran mayormente el río, los campos de trigo y algunas cosas en pequeños pueblos, porque Terry y yo nunca estábamos juntos; hablábamos por teléfono y él me describía lo que quería y yo lo rodaba.

${ }^{41}$ (N. del T.) Delegaba escenas en los directores de la segunda unidad a regañadientes, él quería rodar todo personalmente, ya que sospechaba que lo que el director de la segunda unidad quería era hacer su propia película.

42 To the Wonder, Knight of Cups (Terrence Malick, 2015) y Song to Song (Malick, 2017) son tres filmes a los que a menudo se hace referencia como trilogía, debido en gran parte a la ausencia de un guion, el uso de la cinematografía y el carácter imprevisto del rodaje en las tres producciones.

${ }^{43}$ El título de este spin off es Thy Kingdom Come (Eugene Richards, 2018). Este corto (43 minutos) fue realizado con parte del material de la segunda unidad rodado por Richards para el filme To the Wonder. 
gada linea roja, revela: «The 2nd Unit ended up having 40 minutes of screen time in the final cut ${ }^{44}$ (G. Capo, comunicación personal, 26 de abril de 2018).

La forma en la que Malick colabora con la segunda unidad, concretamente en Días del cielo, es muy similar al trato que mantiene con el resto de departamentos; existen ciertas reglas a seguir que son determinadas por Malick, las cuales tienen como objetivo encauzar la labor de los distintos colaboradores hacia un mismo enfoque. En Días del cielo, la naturalidad y el realismo eran elementos clave para el director, y como Almendros relata:

La labor de todos nosotros se unificó gracias al inmenso talento de Terry, a sus conocimientos técnicos y a su gusto infalible. Pues Malick no permitiría jamás a nadie hacer algo que fuera contra sus ideas. Antes del rodaje se establecieron una serie de principios. Se diseńó el estilo de esta película de tal modo que cada colaborador tenía que seguir por fuerza las pautas trazadas, fundamentalmente la de no falsificar la realidad en la medida de lo posible (Almendros, 1990: 181).

De esta forma, el equipo de la segunda unidad realiza su trabajo siguiendo una serie de instrucciones; en Días del cielo el director no exigió ningún plano en concreto, sino que, como Ryan recuerda, «Terry didn't explain exactly the images that he wanted, but he did explain the feeling, which was sort of someone who discovers open space for the first time» " ${ }^{45}$ (Hintermann et al., 2015: 101); en otras ocasiones, la segunda unidad trabaja de acuerdo a una lista de planos que reciben de Malick, quien previamente la ha esbozado (presumiblemente) teniendo en cuenta la posible cobertura de planos que necesitará para montar el filme. Así pues, el equipo de la segunda unidad debe analizar y organizar junto con Malick la forma en la que rodarán el metraje requerido, ya que puede ocurrir que éste sea demasiado extenso; A.J. Edwards ${ }^{46}$ (2014), director de la segunda unidad en El árbol de la vida, comenta al respecto: «Our shot list was nearly as long as the entire schedule, so we edited it down to what Malick believed was practical and essential according to his needs and vision» ${ }^{47}$ (párr. 7).

La unidad principal se ve sometida a una cierta presión que se genera como resultado de trabajar con un equipo técnico más numeroso, la colaboración con actores principales, el empleo de efectos especiales (a veces), etc. En las producciones de Malick, generalmente, la segunda unidad trabaja bajo unas condiciones distintas a las de la unidad principal, lo que se traduce en un ritmo de trabajo ligeramente más sosegado; esto permite, por ejemplo, la posibilidad de meditar más sobre la com-

44 (N. del T.) La segunda unidad acabó teniendo 40 minutos de metraje en la versión final.

45 (N. del T.) Terry no explicaba exactamente las imágenes que quería, sino que explicaba el sentimiento, que era algo parecido a quien descubre espacio abierto por primera vez.

46 A. J. Edwards ha colaborado con Malick en varias películas, desempeñando la labor de director de la segunda unidad y montaje adicional. En 2014 dirigió su primer largometraje, The Better Angels, el cual fue producido por Malick, entre otros.

47 (N. del T.) Nuestra lista de planos era casi tan larga como el plan de rodaje, así que la resumimos a lo que Malick creía que era práctico y esencial de acuerdo a sus requerimientos y visión. 
posición, iluminación, o el movimiento de cámara para cada plano. Sobre su experiencia con Malick, Edwards (2014) explica: «We had the ability to wait for good light and get the imagery we wanted, or more importantly, what the director wanted. [...] we searched for our shots, rather than artificially creating them $»^{48}$ (párr. 7).

En otro orden de ideas, el material rodado por la segunda unidad debe preservar un cierto estilo estético (que depende de factores como profundidad de campo, distancia focal, iluminación, filtros, etc), el cual queda definido desde el inicio del rodaje principalmente por Malick, el director de fotografía de la unidad principal y, a menudo, el director de arte. Para mantener la coherencia en el look de las imágenes el director de fotografía de la segunda unidad debe discutir los distintos elementos que componen la estética del filme y, a su vez, reconocer cuáles son los aspectos que conforman el estilo del realizador; el director de fotografía John Mahaffie ${ }^{49}$ comenta sobre este tópico: «It's a matter of emulating the style of the filme [...]. My role is to try and see this sort of style, and styles are just that. They tend to be palettes of color or palettes of light $»^{50}$ (McLevy, 2015: párr. 49). Para Malick, el rodaje con luz natural en Días del cielo era un requisito primordial, y, en concreto, buscaba fotografiar la delicada luz de los últimos momentos del día, como Ryan recuerda:

Terry was insistent on filming late into the day when the light was almost gone, "Magic Hour» and beyond. We experimented with fast lenses and pushed filme [...]. We shot tests in very low light conditions and found we could shoot with less exposure than traditionally done ${ }^{51}$ (P. Ryan, comunicación personal, 4 de junio de 2018).

Como se puede comprobar, al igual que Almendros ${ }^{52}$, Ryan también llevaría a cabo una serie de pruebas para ver hasta dónde era posible forzar el filme ${ }^{53}$, lo cual revela parte de su involucración en el proceso creativo.

Puesto que durante el proceso cinematográfico la consistencia del look del metraje es un aspecto clave para el montaje, se podría determinar que la segunda unidad dispone de una libertad creativa bastante limitada, ya que su trabajo está

48 (N. del T.) Disponíamos de la capacidad de esperar para la buena luz y conseguir las imágenes que queríamos, o más importante, las que el director quería. [...] buscábamos los planos, en lugar de crearlos artificialmente.

49 John Mahaffie trabaja habitualmente como director de fotografía/director de la segunda unidad en producciones de gran escala, como, por ejemplo, The Lord of The Rings: The Fellowship of the Ring (Peter Jackson, 2001).

50 (N. del T.) Se trata de emular el estilo de el filme [...]. Mi rol es intentar ver este tipo de estilo, y estilos son justamente eso. Suelen ser paletas de color o paletas de luz.

51 (N. del T.) Terry era insistente en filmar durante los últimos momentos del día cuando la luz casi había desaparecido, hora mágica e incluso más tarde. Experimentamos con objetivos luminosos y forzamos el negativo [...]. Realizamos tests en condiciones lumínicas mínimas y descubrimos que podíamos filmar con una menor exposición que la que se usaba tradicionalmente.

52 Malick y Almendros llevaron a cabo algunos tests en la zona de Lethbridge, Alberta, antes de que la fotografía principal comenzase (Schaefer y Salvato, 2013).

${ }_{53}$ El filme utilizado fue Eastman Kodak 5247 100T. 
subordinado al estilo de la unidad principal; sin embargo, dependiendo de la experiencia y bagaje artístico de cada individuo, puede resultar difícil recrear con precisión el estilo de otro colaborador. Mahaffie opina sobre su trabajo con respecto al de la unidad principal: «I wouldn't say "mimic", because it's always interpretation, because everything I'm doing is completely different or new -but the role is to try and bring that into context ${ }^{54}$ (McLevy, 2015: párr. 49). En Días del cielo, debido a la diferente localización donde se encontraba ( $\mathrm{y}$ al desconocimiento de su participación por parte de Almendros), Ryan realizaba su trabajo al margen de Almendros y Malick, y se comunicaba tan sólo con éste último; acerca de su responsabilidad con respecto al material rodado, Ryan manifiesta:

Shooting the second unit, the most important thing is to have the communication with the director. In Days of Heaven and A River Runs Through It it was much more about a feeling rather than specifics. I had to go out and find things on my own with a kind of freedom, but with the anchor of the visual intent that the director wants ${ }^{55}$ (Hintermann et al., 2015: 117).

Debido a la autonomía bajo la que suele operar la segunda unidad, en ocasiones pueden surgir ciertas dudas entre los miembros de este equipo a la hora de abordar el rodaje de ciertos planos o escenas. Como Kim Marks ${ }^{56}$ admite: «Trying to keep the look consistent is always the biggest challenge -trying to keep the angles, the lighting etc. all the same so it matches the First Unit» ${ }^{57}$ (Martin, 2012: párr. 12). Este aspecto puede contribuir a que se prescinda de la presencia de la segunda unidad en algunos filmes; el director de fotografía Wally Pfister expone su opinión sobre este tema cuando dice: "Quite often, the second-unit insert shots need to be re-shot, or there are continuity problems. It does make sense to have the first unit do them wherever possibles ${ }^{58}$ (Mottram, 2002: 120). Es por este motivo por lo que frecuentemente la segunda unidad rueda bastante material con distintas variaciones, ofreciendo así un abanico más amplio de posibilidades al director.

Por otro lado, en ciertas ocasiones la enorme cantidad de metraje rodado por las distintas unidades puede resultar un inconveniente, desde el punto de vista creativo. Almendros, quien durante su carrera colaboró con varios directores ame-

54 (N. del T.) No diría imitar, porque siempre hay una interpretación, porque todo lo que hago es completamente diferente o nuevo, pero la labor es tratar de integrarlo dentro del contexto.

55 (N. del T.) Rodando en la segunda unidad, lo más importante es comunicarse con el director. En Days of Heaven y A River Runs Through It se trataba mucho más de el sentimiento que de detalles específicos. Tenía que salir y encontrar cosas por mi cuenta con cierta libertad, pero basándome en la intención visual que el director posee.

${ }^{56}$ Kim Marks ha colaborado como director de fotografía de la segunda unidad en distintos films como, por ejemplo, Godzilla (Gareth Edwards, 2014).

57 (N. del T.) Intentar mantener la consistencia del look es siempre el mayor desafío, intentar mantener los ángulos, la iluminación, etc., igual para que coincida con la primera unidad.

58 (N. del T.) Bastante a menudo, los planos insertos de la segunda unidad deben de ser filmados de nuevo, o hay errores de continuidad. Tiene sentido que la primera unidad los filme siempre que sea posible. 
ricanos y europeos, comenta sobre la gran cantidad de metraje que se suele filmar en Hollywood en contraposición a las producciones europeas:

[Americans] use thousands of feet of filme and get much more coverage. They cover everything from every possible angle; [...] there are many more scenes that are never used.

[...] you have a tremendous amount of filme. And it takes more time for editing; you have too many choices, too many angles. With many of the films that I've seen in America, I have the impression that they're always cutting for no reason. ${ }^{59}$ (Schaefer y Salvato, 2013: 20-21)

Puede que, en parte debido a la cantidad de filme rodado y, por consiguiente, la infinidad de opciones que se presentan en el proceso de montaje, las producciones de Malick suelan alargarse durante enormes períodos de tiempo durante esa última etapa; Días del cielo tardó un año en ser editada, aunque en este caso, gran parte de ese tiempo se empleó en la experimentación con diferentes montajes que fueron utilizados para descubrir cuál era la manera más apropiada de dar forma a la narración de acuerdo a lo que el director intentaba transmitir.

Durante la producción de Días del cielo, el director de fotografía estadounidense Haskell Wexler ${ }^{60}$ reemplazaría a Almendros en las dos últimas semanas de rodaje (dado que éste debía comenzar a trabajar en la producción de Truffaut $E l$ hombre que amaba a las mujeres [L'homme qui aimait les femmes, 1977]), y su principal trabajo consistiría en mantener el estilo que Almendros y Malick habían establecido. Almendros rodó durante 53 días en total, y Wexler 19 días. A lo largo de una semana, Wexler y Almendros trabajaron juntos para que Wexler pudiera familiarizarse con el trabajo realizado hasta ese momento. Para Almendros, era muy importante que Wexler continuase trabajando de la misma forma en que él lo había hecho y concretamente le pidió que no utilizase ningún filtro difusor ${ }^{61}$ (los cuales estaban de moda en los años 70 y Wexler solía utilizar), ya que Almendros quería conseguir una imagen clara y con bastante definición. Wexler confesaría posteriormente que usó difusión a veces, como, por ejemplo, en la escena inicial de la planta siderúrgica; Wexler dice haberse sentido culpable por utilizar difusión, como si hubiese

59 (N. del T.) [Los americanos] utilizan miles de metros de filme y filman mucha más cobertura. Cubren todo desde cada ángulo posible; [...] hay muchas más escenas que nunca son utilizadas. [...] tienes una cantidad tremenda de filme. Y lleva más tiempo editarlo; tienes demasiadas opciones, demasiados ángulos. Con muchos de los films que he visto en América, me da la impresión de que siempre cortan sin ningún motivo.

${ }^{60}$ Según Almendros, fue él quien se encargó de escoger a Haskell Wexler para que finalizase el rodaje de Días del cielo, dado que Almendros admiraba su trabajo y le consideraba un amigo (Almendros 1990).

${ }^{61}$ Los filtros difusores se utilizan sobre el objetivo y la forma en la que actúan es dispersando la luz y reduciendo la definición de la imagen registrada en el celuloide/sensor digital. Los filtros difusores más populares en Hollywood, durante el período de finales de los 60 hasta mediados de los 70, eran Fogs, Low-Cons, y Double-Fogs. 
traicionado a Almendros (Maher, 2017). Ahora bien, Wexler ${ }^{62}$ no pertenecía a la segunda unidad, sino que trabajó en la unidad principal, junto con Malick, pero aun así Wexler se desvió ligeramente del procedimiento que Almendros había estado siguiendo hasta el momento de su partida. El hecho de que Wexler decidiera utilizar herramientas distintas a las de Almendros se podría interpretar como la voluntad de expresar un estilo propio, o un aporte personal a la estética de la obra que, pese a haber sido inicialmente diseñada por otros colaboradores, parecía encontrarse en un proceso de continua evolución hasta el momento de su estreno.

De este modo, no resulta incomprensible que algunos directores sean reacios a la hora de confiar en el trabajo realizado por las segundas unidades. Dependiendo de el artista, hay ciertos directores que participan en mayor medida en los distintos departamentos, presumiblemente debido a la influencia que ejerce la figura del auteur en el campo del cine, y por lo tanto prefieren estar involucrados y realizar por sí mismos la mayor cantidad de trabajo posible. El director Christopher Nolan comprende el proceso cinematográfico y presta especial atención a la estética de la imagen; Nolan es un tipo de director que prefiere rodar junto con la unidad principal (siempre y cuando sea posible) todo el material, incluyendo los insert shots y stunts de las escenas de acción. Cuando le preguntan sobre la razón por la cual no suele haber una segunda unidad en sus proyectos, Nolan responde lo siguiente:

If I don't need to be directing the shots that go in the movie, why do I need to be there at all? The screen is the same size for every shot. [...] Everything is equally weighted and needs to be considered with equal care, I really do believe that. I don't understand the criteria for parceling things off ${ }^{633}$ (Ressner, 2012: párr. 50).

Este punto de vista parece sugerir que para Nolan la estructura del filme está bastante clara desde el inicio (en términos de montaje), ya que al encargarse del trabajo que normalmente llevaría a cabo la segunda unidad, este director consigue con cierta precisión el material que necesita, limitando en gran medida la cantidad de metraje rodado. Así pues, de acuerdo al estilo de Nolan, cuanta más cantidad de trabajo sea realizada y supervisada por el director, más aspectos de su persona y visión acabarán formando parte de la obra final. A pesar de ello, Nolan también admite que otros directores de cine son capaces de utilizar segundas unidades de forma satisfactoria (Ressner, 2012).

En el caso de Malick, los miembros de las unidades adicionales realizan un trabajo fundamental para la narración de la obra, como se expone a lo largo de este

${ }^{62}$ Es conocido el descontento que Haskell Wexler mostró inicialmente hacia el crédito de 'Additional Photography' con el que su trabajo fue catalogado en Días del cielo, puesto que Wexler sentía que su labor era equiparable a la de Almendros. En una ocasión Wexler visionó el filme con un cronómetro para probar que más de la mitad del metraje había sido rodado por él (Ebert, 1997).

${ }^{63}$ (N. del T.) Si no necesito dirigir los planos que van en la película, ¿para qué necesito estar ahí en absoluto? El tamaño de la pantalla es el mismo para cada plano. [...] Todo tiene el mismo valor y necesita ser considerado con el mismo cuidado, de verdad lo creo así. No entiendo las razones para querer separar las tareas. 
artículo. Días del cielo fue el primer filme en el que Malick empleó la segunda unidad con la intención de incrementar su paleta tonal y desarrollar así un lenguaje especialmente visual. Pese a que este filme acabó adoptando una forma distinta a la original, su dependencia en la imagen como elemento expresivo era algo que su director había concebido desde el inicio; como Ryan corrobora al recordar su primera conversación con Malick: «He had clear vision in his mind of how the filme would express his ideas visually. He emphasised that the second unit shooting would be a major part of the film $»^{64}$ (P. Ryan, comunicación personal, 4 de junio de 2018).

El tipo de metraje que la segunda unidad aporta en la obra de Malick difiere del resto de producciones en su contenido y propósito. Desde su concepción hasta el momento en que acaban siendo incluidas en el montaje, las imágenes filmadas por estos equipos poseen un cometido que va más allá de la ilustración visual explicativa. Dependiendo en mayor medida de su yuxtaposición con el resto del metraje que del propio contenido, estos planos manifiestan distintas sensaciones, dilatan la narración (en ocasiones incluso la avanzan) y expresan visualmente aquello que no se puede describir. Dejando a un lado el ego, los directores de fotografía de este tipo de unidades se convierten en camaleones (Edwards, 2014), mimetizándose con el estilo del director y la unidad principal e intentando traducir en imágenes las emociones y matices que la historia requiere. En el cine de Malick, la trama deja de ser una autopista donde la narración está constituida por elementos que contribuyen al constante avance de ésta y en su lugar se transfigura en un río, en el que en ocasiones el agua fluye de manera energética en las zonas más amplias y se ralentiza en los remansos (Geisler et al., 2010); es por ello por lo que este director necesita hacer acopio de un tipo de material que le permita expresarse de forma no verbal, enfatizando de este modo el trabajo de los directores de fotografía y la sensibilidad de la que éstos disponen para interpretar y encontrar los elementos narrativos que definen su obra de una forma más notable.

Recibido: abril de 2019. Aceptado: junio de 2019

${ }^{64}$ (N. del T.) Él tenía una visión mental clara de cómo el filme expresaría sus ideas visualmente. Él hacía énfasis en el hecho de que la segunda unidad constituiría una gran parte de el filme. 


\section{BIBLIOGRAFÍA}

Almendros, N. (1990): Días de una cámara, Barcelona, Seix Barral.

Anker, R. (2010, septiembre/octubre): "The Mysterious Nature of Nature»: On the films of Terrence Malick. Consultado el 16 de mayo de 2018, de https://www.booksandculture.com/articles/2010/sepoct/mysteriousnature.html.

Beyda, K. (2013, octubre 25): My most memorable filme: Billy Weber on 'Days of Heaven'. Consultado el 23 de junio de 2018, de http://blogs.artcenter.edu/dottedline/2013/10/25/my-most-memorable-film-billy-weber-on-days-of-heaven/.

Ciment, M. (2007): Pequeño planeta cinematográfico: 50 realizadores, 40 años de cine, 30 países, (F. López Martín, trad.), Madrid, Akal. (Trabajo original publicado en 2003).

Combs, R. (1979): 'The Eyes of Texas', Sight and Sound, 48, 2, 110-11.

Ebert, R. (1997, diciembre 7): Days of Heaven: Review. Consultado el 18 de junio de 2018, de https:// www.rogerebert.com/reviews/great-movie-days-of-heaven-1978.

Edwards, A.J. (2014, octubre 28): What Can You Learn From Second Unit Photography?: Advice from A.J. Edwards of The Better Angels. Consultado el 29 de mayo de 2018, de https://www. moviemaker.com/archives/series/how_they_did_it/aj-edwards-second-unit-photography/.

Fox, T.C. y Riley, B. (1978, septiembre 1): The Last Ray of Light, Filme Comment, 14, 5, 27-31.

Hintermann, C., Villa, D. y Barcaroli, L. (2015): Terrence Malick: Rehearsing the unexpected, London: Faber \& Faber.

Kael, P. (2013): 5001 nights at the movies, New York, Henry Holt and Company.

KeHR, D. (2011): When movies mattered: Reviews from a transformative decade, Chicago, IL, University of Chicago Press.

Lee, H. (2007, diciembre): On the Objects in Days of Heaven. Consultado el 1 de abril de 2018, de http://offscreen.com/view/objects_heaven.

Maher, JR, P. (2017): All Things Shining: An Oral History of the Films of Terrence Malick, S.l., LULU COM.

Malick, T. (1976, junio 2): Days of Heaven. Consultado el 10 de junio de 2018, de https://cinephiliabeyond.org/terrence-malicks-days-of-heaven/.

Martin, P. (2012, julio 24): Interview with Kim Marks (Director of Photography, Second Unit, USA) From The Matrix Reloaded (2003). Consultado el 2 de mayo de 2018, de https://www. matrixfans.net/interview-with-kim-marks-director-of-photography-second-unit-usa-fromthe-matrix-reloaded-2003/.

McLevy, A. (2015, junio 22): What's it like to be a second-unit director on Hollywood blockbusters? Consultado el 11 de agosto de 2018, de https://filme.avclub.com/what-s-it-like-to-be-a-second-unit-director-on-hollywoo-1798280908.

Mediafunhouse (2007, noviembre 22): Jacob Brackman talks about Malick's "Days of Heaven». [Archivo de vídeo]. Consultado el 4 de mayo de 2018, de https://www.youtube.com/watch?v=cCkl3PPT7QQ.

Mottram, J. (2002): The making of Memento, London, Faber \& Faber.

Patterson, H. (2003): The cinema of Terrence Malick: Poetic visions of America, London, Wallflower. 
Phillips, G.D. (2006): Beyond the epic: The life y films of David Lean, Lexington, Ky, University Press of Kentucky.

Ressner, J. (2012, primavera): The Traditionalist. Consultado el 10 de mayo de 2018, de https:// www.dga.org/Craft/DGAQ/All-Articles/1202-Spring-2012/DGA-Interview-Christopher-Nolan.aspx.

Ryan, P. (2009, diciembre): ASC Close-up: Paul Ryan. American Cinematographer, 90(12). Consultado el 11 de abril de 2018, de https://theasc.com/ac_magazine/December2009/ASCClose-Up/page1.html.

SALT, B. (2009): Filme style and technology: History and analysis, London, Starword.

SChaefer, D. y Salvato, L. (2013): Masters of light: Conversations with contemporary cinematographers, Berkeley, Calif, University of California Press.

Silver, C. (2014, agosto 5): Terrence Malick's Days of Heaven. Consultado el 4 de febrero de 2019, de https://www.moma.org/explore/inside_out/2014/08/05/terrence-malicks-days-of-heaven/.

Tarkovskiř, A. A. y Gianvito, J. (2006): Andrei Tarkovsky: Interviews, Jackson, University Press of Mississippi.

Utell, J. (2015): Engagements with narrative, London, Routledge.

\section{Filmografía}

Edwards, A.J. (2014): The Better Angels, USA, Amplify.

Edwards, G. (2014): Godzilla, USA, Warner Bros.

Glassman, A., Samuels, S. (productores) y McCarthy, T. (director) (1992): Visions of light: The art of cinematography, The American Filme Institute and NHK, Japan Broadcasting Corporation, BFI.

Geisler, R. M., Roberdeau, J., Hill, G. (productores) y Malick, T. (director) (2010): The Thin Red Line [DVD], Irvington, NY, Criterion Collection.

JaCkson, P. (2001): The Lord of the Rings: The Fellowship of the Ring, USA, New Line Cinema

Malick, T. (1978): Days of Heaven, Hollywood, Calif, Paramount Pictures.

Malick, T. (1998): The Thin Red Line, United States, Twentieth Century Fox.

Malick, T. (2005): The New World, United States, New Line Cinema.

Malick, T. (2011): The Tree of Life, United States, Fox Searchlight Pictures.

Malick, T. (2013): To the Wonder, United States, Magnolia Pictures.

Malick, T. (2015): Knight of Cups, United States, Broad Green Pictures.

Malick, T. (2017): Song to Song, United States, Broad Green Pictures.

Richards, E. (2018): Thy Kingdom Come, United States, Beyond the Trees.

Schneider, H., Schneider, B. (productores) y Malick, T. (director) (2010): Days of heaven [Bluray], New York, NY, Criterion Collection.

Truffaut, F. (1970): L'enfant sauvage, France, Les Artistes Associés.

Truffaut, F. (1977): L'homme qui aimait les femmes, France, United Artists. 
